\title{
Talking Terms: Choosing and Using Terminology for EFL Classrooms
}

\author{
Roger Berry \\ Department of English, Lingnan University \\ Tuen Mun, Hong Kong \\ E-mail: rogerb@ln.edu.hk
}

\begin{abstract}
This paper discusses the use of grammatical terminology in English language teaching. Accepting that it is a common feature of many classrooms, the paper attempts to help teachers understand the role and nature of terminology. A distinction is made between terms which are transparent (e.g. 'countable'), opaque (e.g. 'verb') or iconic (e.g. '-ing form'). A number of criteria for evaluating the suitability of terminology for classroom use are also offered. In this way it is hoped that teachers will be better equipped to make well-informed decisions about the terms they choose to use in the classroom.
\end{abstract}

Keywords: Terminology, Grammar, Pedagogic

\section{Introduction: the relevance of grammatical terminology}

The use of grammatical terminology in the language classroom has received little practical discussion, perhaps because it is considered incompatible with most approaches to language teaching in the late twentieth century. However, while some critics have associated terminology with all the ills of the grammar-translation method (e.g. Garrett 1986), the majority seem to approve of its limited use, e.g. Woods (1994), Muhammad (1994) and Carter (1995). This quote from Lewis is typical of the positive but cautious approach to that now seems to be current:

Introducing unnecessary jargon into the classroom is intimidating and unhelpful, but the careful introduction and regular use of a few well-chosen terms can be helpful and save a lot of time over the length of a course for both teacher and learner. (2000:129)

And it does seem to play a part in many classrooms. In my study of secondary and tertiary English teachers' use of and attitudes towards terminology in Hong Kong (Berry 2001), the vast majority reported using 'some' or 'a lot' (46 out of 49 secondary and 21 out of 22 tertiary teachers), as opposed to 'little' or 'none'.

Nevertheless, there are problems with the use of terminology in ELT. In an earlier study of teachers and students on a business communication course I found a trend towards extensive overuse of terminology (Berry 1997). Many terms that the teachers assumed learners to be familiar with were generally unknown, and there was wide variation among the learners. Out of 372 students the scores on a 50-item terminology test ranged from 8 to 35 .

Of course, this is not an argument against grammar terminology per se. It merely shows the need for better teacher education. If, as Wright has suggested (1991:68-69), there is a danger in giving teachers specialist knowledge in that that may wish to show it off to learners, then there is a case on training courses for making clear the difference between what teachers need to know and what learners need to know. Similarly, in the classroom teachers must check what terms are known and spend time on those that are not (possibly in self-access mode).

In any case, whether teachers use terminology seems to be determined not so much by methodological factors as by personal ones. There is evidence that one of the majors determinants of terminology use is the teachers' own background, i.e. whether their own teachers used much terminology and whether they have had a formal course in English grammar (Berry 2001:112-115). In a similar vein, Borg (1998, 1999) shows how teachers have practices regarding terminology based on their background beliefs and attitudes. There are also factors outside the teacher's control, such as the presence of terminology in textbooks, or its usefulness for learners in self-study mode. The advisability of having terminology in the L1 context, particularly to help the teaching of writing, is uncontested (Cajkler and Hislam 2002, Robinson 2005).

To exemplify how effective terminology can be if used appropriately, I reproduce below an exchange from Tsui (1995:33) in which a teacher is going through student errors involving the incorrect use of verb forms after modals:

T: You can write programmes, play a game, doing calculations, drawing a picture, etc. I like the idea very much, you've got some concrete examples, but it's not quite balanced so far as grammar goes. OK, what is the modal 
in that sentence?

Ss: Can.

T: $\quad$ Can. OK, and we see here the modal (points at the previous sentence on the board)... (my italics; underlined text represents text being cited)

Tsui is not aiming to promote the use of terminology; her interest is in describing good grammatical explanations. But it is hard to imagine a practical alternative to the use of the term modal here (provided students are familiar with it). There will be situations where terminology is not appropriate, as with less advanced, younger or less mature students, but if the classroom focus is on form it appears to be an essential shorthand.

\section{Types of terms}

How then might teachers approach the use of terminology? How can they answer practical questions like: are there any dangers associated with the terms I use? which terms should I use anyway? in the case of synonyms, why is one term better than another? In the next section I will suggest some criteria that teachers (and trainers) can use for evaluation. But first, in order to raise awareness of the nature of terminology, I would like to present a limited taxonomy of terms.

\subsection{Transparency}

Transparency is where the meaning of the term indicates what its referent is about (e.g. countable). Transparency would appear to be an ideal quality, especially pedagogically. It makes sense to use terms that give learners a clue to the meaning of the term - words which they can 'see through'. Typically the clue is given by the 'meaning' of the grammatical item (the past tense 'refers to the past'), but it can also derive from the function, e.g. the job of a connective in grammar is to connect.

There are, however, some problems with transparency. Firstly, there may not be an obvious word available to describe a grammatical category or concept. How could we make up a transparent replacement for terms such as noun? Would thing-like word do? ${ }^{1}$

A more serious problem with such terms is: are they accurate? It is my experience that learners (and teachers) assume this unfailingly to be so (if they know the meaning). Thus the present tense is inevitably associated with present time, even though it is well known that it often implies future (We leave tonight) or general time (The sun rises in the east). This leads some grammarians to call it the non-past tense (as opposed to the past tense). Another problematic term is continuous; a case study at the end evaluates it for transparency and other factors in comparison with progressive.

Another problem with using transparent terms is to do with the concept of distinctiveness, i.e. whether the term can be recognised as a term and not part of the regular vocabulary. Terms in scientific grammar achieve this through coinage, e.g. non-count or uncount in place of uncountable. In the pedagogic context distinctiveness is usually a less pressing need, but it comes to the fore when it is necessary to use the word in a non-terminological sense in the same text, as in this example from Murphy (1994):

For the past we use must have ...(page 56)

Does 'past' here imply that 'must have' is the past tense equivalent (of must) or merely that is used for past time reference?"

But perhaps it is too much to expect total accuracy and distinctiveness. The real issue is: does a term help more than it hinders? Or will it mislead learners into misapprehensions about English grammar? Studies of the usefulness of such terms are sadly lacking.

\subsection{Opaqueness}

Opaqueness is where there is no obvious relationship between the term and its referent (e.g. adjective); learners have no clue from the term as to what it is about. Opaque terms are safe because learners will not make any false associations based on them. They come without the complications of already-existing words and can be precise in meaning.

The most common terms in English, those for word classes, are opaque: noun, verb, adjective, etc. Beyond these, however, the majority of pedagogic grammar terms tend not to be opaque. It is only at the level of scientific grammar that we find an abundance of opaque terminology, e.g. epistemic, paucal, etc. Typically, these words are of Latin or Greek origin, and for those who are familiar with these languages these terms may not be so opaque. And there may be a clue from similar words that have also been borrowed.

The main disadvantage with opaque terms is the learning load they impose on learners. In addition to the concept, a new word has to be learnt, which may be complicated by their length (they tend to be polysyllabic), spelling and pronunciation (the learners may not be familiar with the rules that govern Latinate vocabulary).

\subsection{Iconicity}

As we have seen, there are problems with both of the above types. There is a third solution to the problem - one that is unique to metalinguisitc terminology - which relies on a formal rather a meaning relationship (or lack of it) between 
term and referent. If transparent terms are too misleading and opaque terms too difficult, why not simply use the form itself? For example, a teacher can say 'use '-ing' here' (or 'an '-ing' form').

Such iconic terms are limited in their application; situations where a formal feature is distinctive of a grammatical phenomenon are rare. For example, to express noun in an iconic way would be impossible; we would have to talk about 'any word that ...' and then list several distinctive features. But where they are available, iconic terms represent an unambiguous way of denoting the referent. They may not give any clue to the meaning, as transparent terms do, but this may not be necessary anyway. And they tend to be short.

Here I am thinking about morphemes (rather than words) since they offer the level of generalisation required. However, most basic English morphemes are multifunctional: '-er' is used for the comparative of adjectives as well as agent nouns and '-ed' turns up in the past tense and past participle. Then there is the problem of irregularity; '-ed' is not the only way to refer to past tense and participle. Transformational-generative grammar used to refer to the past participle ending as '-en' - a more distinctive, yet less precise term.

Another issue is how to pronounce iconic terms. Even in writing they may look strange (at least at first) but in speaking they may not be understood at all. There is a choice between either spelling them out ('an I-N-G form' or trying to imitate their pronunciation in connected speech. While either approach might work for '-ing', for the majority of common morphemes the spelled-out version is preferable since the alternative may not be clear; imagine the confusion caused by a teacher saying 'you need an '-er' adjective here'.

Iconicity is applicable only to a limited number of morphemes in English - to those which can be generalised, which means inflectional and a few derivational morphemes. The vast majority of derivational morphemes, e.g. those that turn some verbs into nouns, do not have enough generalisability. You wouldn't say 'No, you need a '-tion' noun here' (however pronounced). Another limitation is that you cannot use them to introduce the form itself: you cannot say 'you form the '-er' form of adjectives by adding '-er' (or '-r')'.

The above discussion has so far concerned the choices facing a teacher when introducing terminology. But we should not forget the possibility of learner-generated terms (Francis 1994). And in this respect iconic terminology is most useful.

\subsection{Eponymous terms}

A sub-class of iconic terms is what I call 'eponymous' terms. We don't need any special term to refer to a grammatical phenomenon that is one of a kind, for example 'used to'. It would be particularly perverse to invent a term for this (the 'habitual past semi-modal'?). We refer to used to (the grammatical item) by saying 'used to' (the terminological item); it refers to itself. And this of course is what we do all the time without thinking; we use the word itself as a term. The vast majority of terminology (if we want to call it that) falls into this category. There of a lack of distinctiveness but it is surely more economical. The simplest argument against talking about the 'future tense' is that it is simply unnecessary; why not say 'will'? There are, however, two cases where a single word does have its own non-iconic term: the definite and indefinite articles. The reader is invited to judge which type is preferable.

The number of purely iconic terms in English is quite limited, but there are many mixed terms where an iconic element is combined with another. Perhaps the best-known example is third-person -s, where the iconic part comes second, but it is more normal for it to be first, as with e.g. -ing adjectives, as used in Cobuild and elsewhere. Other common semi-iconic terms are $\boldsymbol{w h}$ - words or $\boldsymbol{w h}$ - question words, to infinitive, that clause.

\subsection{Summary}

So which type is best? The answer, for the pedagogic arena, where ease of learning is paramount, must be transparent terms where possible. Iconic terms, though user-friendly and confusion-free, are very limited in their applicability (excluding eponymous terms, of course), and the potential distinctiveness of opaque terms is not enough to set against the learning load they impose. But teachers do need to evaluate transparent terms carefully to make sure they are not misleading.

\section{Evaluating terms}

In this section I want to discuss what makes a good or useful term in the pedagogic context. It is important to stress 'pedagogic' here; in scientific grammar factors such as distinctiveness and precision of meaning are paramount, but in pedagogic grammar these may conflict with other criteria.

I have already suggested that transparency is a positive feature of pedagogic terms when we are considering the relationship between the term and its referent. However, there are a number of wider factors that need considering. These are learnability, familiarity, theoretical validity, systematicity, utility and productivity.

\subsection{Learnability}

If learners are to understand, and perhaps use, terms, they need to acquire them in the same way they acquire ordinary 
vocabulary. This makes ease of learning important. A number of factors are involved:

- length. Many terms are polysyllabic, and are a challenge to the productive or receptive limits of learners.

- confusability. Scientific language terminology abounds with pairs of terms that are easily confused, especially where an ending has been added to make a new item. For example:

\section{adverb - adverbial}

subjunct - subjunctive

There is room for only one member of these pairs in pedagogic terminology, even if both concepts are necessary.

- difficulty of spelling/pronunciation. Words of Latin and Greek origin, which many terms tend to be, are harder for most learners - they don't conform to the basic rules of spelling/pronunciation relationships that learners have been brought up on (for example, the pronunciation of final 'e' in 'apostrophe'). There may be other eccentricities, such as the nasal vowel in 'genre'.

This last factor is more relevant in situations where learners are expected to make use of the terms themselves, rather than merely identify what the teacher is referring to.

\subsection{Familiarity}

Teachers going into a class, or grammarians writing a grammar, do not have a free choice; they must ask themselves what prior knowledge their learners/readers bring with them. Some grammarians might want to introduce a totally new terminology, free of all the inconsistency and problems of the current terms, but traditional English grammatical terminology is firmly ensconced in EFL/ESL culture, and innovators ignore this at their peril.

The same is true of those working with teachers. The difficulty of devising new (functional) terminology is articulated by Lock and Tsui, in attempting to provide the terminology for a database of English grammar:

In achieving this aim, we were mindful that it was important not to devalue the kind of knowledge about grammar that many of the teachers already have. Moreover, to help teachers in their construction or re-conceptualisation of grammar knowledge, we must start from their existing knowledge. In particular, we wanted to avoid giving teachers a new set of terms to talk about what they may feel they have long been able to talk about quite satisfactorily in their own terms. (2000:19)

Similarly, Walsh (2003), discussing a course for trainee-teachers, laments the absence of metalanguage for talking about interactional processes.

\subsection{Theoretical validity}

This criterion refers to whether the terminology is consistent with the theories of language and language learning that underpin the teaching. I am thinking in particular of the distinction between meaning and form-based terminology. To some extent, this criterion is at odds with the previous one; since most of the terminology is form-based and is firmly ensconced, there is little room for theoretical manoeuvring.

Nevertheless, there are certain situations where teachers have a choice, or need to appreciate the theoretical overtones that accompany a term. The choice between 'if' sentences and conditionals (on the surface a choice between a partly iconic term and a semi-transparent one) is also a matter of form versus meaning. The two are not entirely synonymous; there are 'if' sentences which are not conditional in meaning and other ways of expressing conditions that do not use 'if' (e.g. via inversion).

Meaning-based teaching is of course possible with form-based terminology, but there is a danger of the dog wagging the tail: because most current terminology is form-based, teachers (and textbook writers) may be lured into focusing on formal features exclusively and ignoring any connection with meaning.

\subsection{Systematicity}

What this concept means in the classroom, as well as in grammars, is that terms cannot always be chosen in isolation; they need to fit in with other terms which belong to the same system. For example, there is little point in using definite article without indefinite article (and vice versa), and the same is true for many other pairs such as past and present, singular and plural. The issue is slightly different when one of the two terms in a pair is marked (e.g. passive as opposed to active), but even here once the marked term has been introduced we will struggle to do without its partner. Another issue is whether the superordinate term is needed; the answer is generally not. Thus voice can be dispensed with; teachers can simply say 'use the passive here'.

\subsection{Utility}

What I mean by utility is: how many words does the term apply to and how important are those words? In other words, how frequently is the term likely to appear in teaching? There is no point introducing a term that will have little use. A term like plural can apply to all nouns (and to some pronouns and determiners) and so has a high utility value. 


\subsection{Productivity}

Productivity is to do with whether a term can be freely combined with other terms to refer to related concepts; 'combinability' might be another way of saying it. Through productivity the number of terms needed can be reduced, or the number of concepts referred to can be increased. For example, tense is productive as a term because it can go with present and past (and maybe future) and all the further combinations such as present perfect . Productivity is particularly appropriate with iconic terms. For example, once you decide to use a term like '-ing' you find that it can be used in a number of terminological phrases: '-ing participle', '-ing adjectives', '-ing nouns'.

\section{A case study: progressive vs continuous}

These two terms apply to the same grammatical concept, namely one option in the aspect system of English ( $I$ am singing); they may be said to be synonymous. But which is preferable?

Both terms are transparent, but continuous is more obviously so. Learners can easily identify it with the idea of continuity, especially if its explanation goes something like this: 'you use continuous forms for actions that are continuing'. The problem is that continuous forms often do not refer to continuous actions (He's been ringing all day), while other forms can have an idea of continuity (I've lived here for years).

Progressive is less likely to be misleading; its basic meaning of 'modern/eager for change' bears little resemblance to anything grammatical, and if it is associated with the idea of something being 'in progress', then it can be argued that this is more accurate (see e.g. Huddlestone and Pullum 2002:163).

In terms of learnability, there is little to choose between them (though I have found that some learners confuse progressive with possessive). In terms of theoretical validity, utility and productivity there is no difference; both are, respectively, form-focussed, likely to be frequently used, and available for combination with other items such as present and past).

It is in familiarity that the greatest difference lies. From personal experience continuous is much better known among learners and teachers, and my study of Hong Kong students (Berry 1997) supports this: present continuous tense was known to $94.6 \%$ while present progressive tense was known only to $7.6 \%$. In a parallel survey of first-year English majors at universities in three countries there was a similar picture: in each case the former was better known (to 80 versus 36 out of 98 Polish students, to 32 versus 26 out of 75 Austrian students, and to 112 versus 16 out of 123 Hong Kong students).

However, in scientific grammar, progressive is the term of choice (e.g. in Huddlestone and Pullum 2002, Biber et al. 1997, Quirk et al. 1985; of these, only the latter refers to continuous, as an alternative term, while the other two make no mention). And this may be influencing pedagogic grammars; Swan (1995) likewise only mentions progressive.

So which term should teachers choose? There is no easy answer here. It is a trade-off between the potentially misleading transparency of continuous and the more accurate but less transparent nature of progressive, as well as between the popularity of continuous and the lack thereof of progressive (though this may be changing). It may be best then for learners to be familiar with both; while they are likely to encounter one in the classroom, the other may appear in a reference grammar, without any cross-reference.

\section{Conclusion}

From all the above discussion, it can be seen that there is always a trade-off when selecting and using terms. In terms of type, transparent terms seem to be preferable, given their ease of learning, but they suffer from a number of problems. They can be misleading, they are rarely available and they lack distinctiveness. Opaque terms by definition cannot mislead but impose a learning burden on the learner. Iconic terms (if we exclude the eponymous sub-class) are again rare of application, but are easily identifiable.

In terms of the criteria for evaluating terms, there are similar trade-offs. Familiarity, for example, may be at odds other criteria. In other words, the perfect term does not exist. But this makes it all the more important for teachers to be able to evaluate the relative merits of the terms they choose to use.

\section{References}

Berry, R. S. (1997). Teachers' awareness of learners' knowledge: the case of metalinguistic terminology. Language Awareness 6, 136-146.

Berry, R. S. (2001). Hong Kong English teachers' attitudes towards the use of metalinguistic terminology. Asian Pacific Journal of Language in Education 4, 101-121.

Berry, R. S. (forthcoming). EFL majors' knowledge of metalinguistic terminology: A comparative study. Language Awareness.

Biber, D. S. Johansson., G.Leech, S. Conrad. \& E. Finegan. (1999). Longman Grammar of Spoken and Written English. 
Harlow: Pearson Education.

Borg, S. (1998). Teachers' pedagogical systems and grammar teaching: a qualitative study. TESOL Quarterly 32/1.

Borg, S. (1999). The use of grammatical terminology in second language classroom: a qualitative study of teachers' practices and cognitions. Applied Linguistics 21/1.

Cajkler, W. \& J. Hislam. (2002). Trainee teachers' grammatical knowledge: the tension between public expectation and individual competence. Language Awareness 11/3.

Carter, R. (1995). How aware should language aware teachers be? In D. Nunan, R. Berry and V. Berry (eds.) Language awareness in Language Education (pp.1-15). Department of Curriculum Studies, University of Hong Kong.

Garrett, N. (1986). The problem with grammar. Modern Language Journal 70, 133-47.

Francis, G. (1994). Grammar teaching in schools: what should teachers be aware of? Language Awareness $3 / 3$ \& 4 .

Huddlestone, R. \& G.K. Pullum. (2002). The Cambridge Grammar of the English Language. Cambridge: Cambridge University Press.

Lewis, M. (2000). Language in the lexical approach. Chapter 7 in Teaching Collocation: Further Developments in the Lexical Approach, M. Lewis (ed.). Hove: Language Teaching Publications.

Lock, G. \& A. B. M. Tsui (2000). Customising Linguistics: developing an electronic grammar database for teachers. Language Awareness 9/1.

McArthur, T. (1996). The Oxford Companion to the English Language (abridged edition). Oxford: Oxford University Press.

Mohammed, A. (1994). Grammar instruction in language development. Language Awareness 4, 49-58.

Murphy, R. (1994). English Grammar in Use. Cambridge: Cambridge University Press.

Quirk, R., S. Greenbaum., G. Leech. \& J. Svartvik. (1985). A Comprehensive Grammar of the English Language. Harlow: Longman.

Robinson, M. (2005). Metalanguage in L1 English-speaking 12-year-olds: which aspects of writing do they talk about? Language Awareness 14/1.

Swan, M. (1995). Practical English Usage. Oxford: Oxford University Press.

Tsui, A. M. B. (1995). Introducing Classroom Interaction. London: Penguin.

Walsh, S. (2003). Developing intercultural awareness in the second language classroom through teacher self-evaluation. Language Awareness, 12/2.

Woods, E. (1994). Introducing Grammar. London: Penguin.

Wright, T. (1991). Language Awareness in teacher education programmes for non-native speakers. In C. James and P. Garrett (eds.) Language Awareness in the Classroom. London: Longman.

\section{Notes}

1. In fact, German attempts this for verb: 'Zeitwort' (literally 'time-word'). But 'Verb' also exists.

2. There is a traditional, opaque alternative for past, namely preterite (McArthur 1996:722), and this is used in the Cambridge Grammar of the English Language (Huddlestone and Pullum 2002). However, it has no currency in pedagogic circles. 